\title{
Pharmacotherapy for closure of large patent ductus arteriosus in preterm neonates: Fail once, not twice
}

\author{
Stephanie L. Perrier, MD, ${ }^{a}$ and Igor E. Konstantinov, MD, PhD, FRACS ${ }^{\mathrm{a}, \mathrm{b}, \mathrm{c}}$
}

\footnotetext{
From the a Department of Cardiac Surgery, Royal Children's Hospital, Melbourne, Victoria, Australia; ${ }^{\mathrm{b}}$ Heart Research group, Murdoch Children's Research Institute, Melbourne, Victoria, Australia; and ${ }^{\mathrm{c}}$ Melbourne Children's Centre for Cardiovascular Genomics and Regenerative Medicine, Melbourne, Victoria, Australia. Disclosures: Authors have nothing to disclose with regard to commercial support.

Received for publication June 24, 2018; revisions received June 24, 2018; accepted for publication June 25, 2018; available ahead of print Aug 14, 2018.

Address for reprints: Igor E. Konstantinov, MD, PhD, FRACS, Royal Children's Hospital, Flemington Rd, Parkville, Victoria 3029, Australia (E-mail: igor.konstantinov@rch.org.au).

J Thorac Cardiovasc Surg 2018; 156:1935-6

$0022-5223 / \$ 36.00$

Crown Copyright (C) 2018 Published by Elsevier Inc. on behalf of The American Association for Thoracic Surgery https://doi.org/10.1016/j.jtcvs.2018.06.073
}

A very interesting, thought-provoking, and important article written by Mashally and colleagues ${ }^{1}$ is published in this issue of the Journal. They studied a challenging group of preterm infants in whom conventional medical therapy failed to close patent ductus arteriosus (PDA). They aimed to determine whether subsequent acetaminophen administration would effectively close the PDA, thus obviating the need for surgery. Indeed, it appears that such administration of acetaminophen may decrease the need for surgical closure of PDA. It remains unknown, however, whether the same decrease in need for surgery may be achieved by merely waiting longer. ${ }^{2}$ In fact, in as many as $40 \%$ of low-birth weight premature neonates, the PDA will close spontaneously by postnatal day $8 .^{3}$ The rate of spontaneous ductal closure beyond this period is unknown, because most neonatologists would attempt to close PDA medically or surgically by then. If the medical therapy, indomethacin or ibuprofen, fails, most infants would have surgical closure of the PDA by about 3 or 4 weeks after birth. ${ }^{4}$

Mashally and colleagues ${ }^{1}$ have demonstrated that the rate of surgery can be decreased with acetaminophen. At what cost? It appears that prolonged exposure to PDA circulation was associated with about 3 -fold increased risk of chronic lung disease. Although not directly comparable, infants who received acetaminophen treatment had significantly longer exposure to PDA circulation than did those infants who received surgical closure (41 days vs 28 days; $P<.01)$. Moreover, roughly half of the infants who underwent acetaminophen treatment still required surgical PDA closure. Does a 20\% reduction in the need for low-risk surgery justify a prolonged exposure to PDA circulation, with increased risk for subsequent chronic lung disease? How do we define a success or a failure? Should successful medical closure of PDA at cost of a more than 3-fold increase in chronic lung disease be considered a success or a failure of medical management?

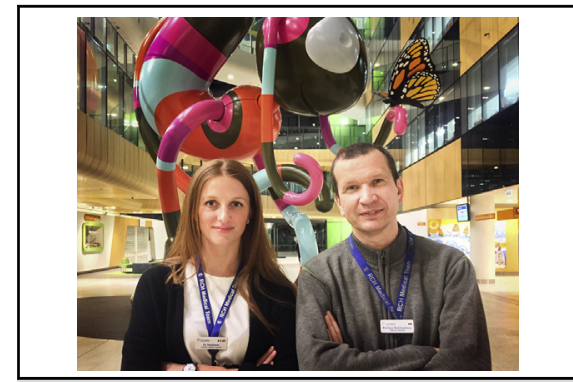

Stephanie L. Perrier, MD (left), and Igor E. Konstantinov, MD, PhD, FRACS (right)

\section{Central Message}

Delaying surgical closure of patent ductus arteriosus after failed pharmacotherapy may increase the incidence of chronic lung disease in premature infants.

See Article page 1937.
In a view of exceptionally low mortality and morbidity related directly to surgical closure of PDA, it might be a mistake to subject the infants to the risks associated with prolonged exposure to a large PDA. It appears that the risks of prolonged exposure to PDA outweigh the exceptionally small risk of surgical PDA ligation.

It might be appropriate to mention a famous quote attributed to Roman statesman Marcus Tullius Cicero (106-43 BC), "Cuiusvis hominis est errare, nullius nisi insipientis in errore perseverare," which can be translated from Latin as, "Any man can make a mistake; only a fool persists making the same mistake." The judgment in medicine is often difficult. What is a mistake, and what is not? Intuitively, it appears that if medical therapy fails once, it may not be prudent to persist with yet another medical therapy merely to decrease the need for low-risk surgery, particularly at a cost of significant medical morbidity. Despite the feverish research activity, the question on the optimal time and method of PDA closure remains unanswered. ${ }^{4}$ Will there ever be a randomized controlled trial to provide a definitive answer? It is yet to be seen.

\section{References}

1. Mashally S, Nield LE, McNamara PJ, Martins FF, El-Khuffash A, Jain A, et al Late oral acetaminophen versus immediate surgical ligation in preterm infants with persistent large patent ductus arteriosus. J Thorac Cardiovasc Surg. 2018; 156:1937-44. 
2. Bose CL, Laughon MM. Patent ductus arteriosus: lack of evidence for common treatments. Arch Dis Child Fetal Neonatal Ed. 2007;92:F498-502.

3. Chiruvolu A, Punjwani P, Ramaciotti C. Clinical and echocardiographic diagnosis of patent ductus arteriosus in premature neonates. Early Hum Dev. 2009;85:147-9.

4. Mitra S, Florez ID, Tamayo ME, Mbuagbaw L, Vanniyasingam T, Veroniki AA, et al. Association of placebo, indomethacin, ibuprofen, and acetaminophen with closure of hemodynamically significant patent ductus arteriosus in preterm infants: a systematic review and meta-analysis. JAMA. 2018;319:1221-38.

5. Cassady G, Crouse DT, Kirklin JW, Strange MJ, Joiner CH, Godoy G, et al. A randomized, controlled trial of very early prophylactic ligation of the ductus arteriosus in babies who weighed $1000 \mathrm{~g}$ or less at birth. $N$ Engl J Med. 1989;320:1511-6. 